\title{
Nitrogen Sparing Induced by Leucine Compared with That Induced by its Keto Analogue, $\alpha$-Ketoisocaproate, in Fasting Obese Man
}

\author{
William E. Mitch, Mackenzie Walser, and Daniel G. Sapir, Department of \\ Pharmacology and Experimental Therapeutics and Department of Medicine, \\ Johns Hopkins University School of Medicine, Baltimore, Maryland 21205
}

\begin{abstract}
A в S TRACT We measured the effects of seven consecutive daily infusions of $\alpha$-ketoisocaproate (the $\alpha$-keto analogue of leucine) or leucine itself on urinary urea and total nitrogen excretion during fasting. Two study protocols were undertaken. In protocol I, subjects underwent three separate 14-d fasts: one during which $34 \mathrm{mmol} / \mathrm{d}$ of leucine were infused on days $1-7$; a second during which $34 \mathrm{mmol} / \mathrm{d}$ of $\alpha$-ketoisocaproate were infused on days 1-7; and a third control fast during which no infusions were given. Infusions of $\alpha$-ketoisocaproate significantly reduced daily urine urea nitrogen excretion compared with both the control fasts and the fasts in which leucine was infused $(P<0.001)$. This nitrogen-sparing effect of $\alpha$-ketoisocaproate persisted during days 8-14 even though no further infusions were given. Daily urinary urea nitrogen excretion during fasts when leucine was administered did not differ from values observed during control fasts. In protocol II, subjects were starved on two occasions for $14 \mathrm{~d}$. During one fast, infusions of $11 \mathrm{mmol} / \mathrm{d}$ of $\alpha$-ketoisocaproate were given on days 1-7; during the control fast, no infusions were given. Daily urine urea nitrogen excretion was lower $(P<0.001)$ on days $1-7$ and also on days 8-14 of the fast during which $\alpha$-ketoisocaproate was given.
\end{abstract}

The nitrogen-sparing effect of $\alpha$-ketoisocaproate could not be related to changes in circulating levels of amino acids, ketone bodies, or insulin in either protocol.

An Abstract pertaining to this work was published in 1978 . Clin. Res. 27: 373A.

Dr. Mitch's present address is Department of Medicine, Peter Bent Brigham Hospital, Boston, Massachusetts 02115. Dr. Mitch is the recipient of Research Career Development Award AM 00750. Dr. Sapir is the Irving Blum Scholar in Renal Disease. Address reprint requests to Dr. Daniel G. Sapir.

Received for publication 21 April 1980 and in revised form 8 October 1980 .
We conclude that $\alpha$-ketoisocaproate infusions decrease the nitrogen wasting of starvation, whereas leucine, studied under identical conditions, does not.

\section{INTRODUCTION}

In in vitro experiments, branched-chain amino acids, particularly leucine, have been shown to stimulate protein synthesis in skeletal muscle $(1,2)$. In addition, leucine has been reported to diminish the rate of muscle protein degradation of the isolated rat hemidiaphragm (1), an effect which is apparently attributable to its $\alpha$-keto analogue, $\alpha$-ketoisocaproic acid. In man, infusion of valine, isoleucine, and leucine has been shown to reduce nitrogen wasting during the immediate postoperative period (3). Finally, it has been reported recently that infusion of leucine improved nitrogen balance of fasting individuals in addition to decreasing glucose turnover and the concentrations of circulating plasma amino acids (4). Thus, leucine and/or its metabolic products appear to have an important regulatory role in protein metabolism of man, as well as the experimental animal.

In fasting human subjects, infusion of a combination of the $\alpha$-keto analogues of valine, leucine, and isoleucine decreases urea nitrogen excretion and improves nitrogen balance (5). Comparable experiments with the three branched-chain amino acids themselves have not been carried out. To determine whether leucine, administered as such or as its $\alpha$-keto analogue is more effective in promoting nitrogen sparing during starvation, we have compared the effects of equimolar infusion of leucine and $\alpha$-ketoisocaproate on urea nitrogen and total nitrogen excretion of fasting subjects. To determine whether the nitrogen-sparing effect of infusing the $\alpha$-keto analogues of leucine, valine, and isoleucine in the previous study (5) was attributable entirely to the leucine analogue, we also examined the effects on nitrogen excretion of infusing $11 \mathrm{mmol} / \mathrm{d}$ of 
$\alpha$-ketoisocaproate, the quantity administered during the previous study.

\section{METHODS}

Two male and nine female volunteers participated in one or both of two study protocols. Informed consent was obtained for starvation protocols and for infusions of leucine or $\alpha$-ketoisocaproate. The average age of the subjects was $37 \mathrm{yr}$ (range 20-61). Their average weight upon entering the first study was $135 \mathrm{~kg}$ (range $74.5-200 \mathrm{~kg}$ ) and their average height was $163.8 \mathrm{~cm}$. They averaged $222 \%$ of ideal body weight (based on 1959 Metropolitan Life Insurance Company Tables; Metropolitan Life Insurance Company, New York). No patient had a fasting blood glucose greater than $120 \mathrm{mg} / \mathrm{dl}$ or evidence of abnormal cardiac, thyroid, hepatic, or renal function. During the $4 \mathrm{~d}$ before beginning a study, the subjects ate diets consisting of at least $2,500 \mathrm{kcal} / \mathrm{d}$ containing a minimum of 300 $\mathrm{g} / \mathrm{d}$ of carbohydrate and $75 \mathrm{~g} / \mathrm{d}$ of protein. They were taking no drugs with the exception of one female subject who took $40 \mathrm{mg} / \mathrm{d}$ of megesterol acetate throughout her studies.

In protocol I, five females and one male each underwent three separate fasts, each fast lasting $14 \mathrm{~d}$. During the first 7 $\mathrm{d}$ ' of one fast, they received a daily intravenous infusion of 34 mmol of sodium $\alpha$-ketoisocaproate in $250 \mathrm{ml}$ water over a 2-3 $h$ period. During the first $7 \mathrm{~d}$ of a second fast, they were infused with $34 \mathrm{mmol}$ of leucine contained in $500 \mathrm{ml}$ of $0.45 \%$ $\mathrm{NaCl}$ over a 3-h period. During the third fast, which served as a control, they received no infusions.

In protocol II, four females and two males each fasted for two 14-d periods. During the first $7 \mathrm{~d}$ of one fast, they received a daily intravenous infusion of $11 \mathrm{mmol}$ of sodium $\alpha$-ketoisocaproate in $150 \mathrm{ml}$ of water administered over a 2 -h period. During the other fast, no infusions were given (control study).

In each of the two protocols, 4 wk or more separated each fast, and the sequence of the study, with respect to the infusions and the control fast, was varied.

Blood sampling. For determination of various metabolites, venous blood was drawn without stasis just before infusion on the 1st and 7th $\mathrm{d}$ and again $1 \mathrm{~h}$ after completion of the infusion. Blood was also drawn at completion of the fast on the morning of day 15. During the control fasts, blood was drawn on the morning of the 7th and 15th $\mathrm{d}$.

Analytical methods. Supernates prepared from sulfosalicylic acid-LiOH (pH 1.80) and precipitates of plasma were frozen until analyzed for amino acid concentrations using a Beckman 119 amino acid analyzer (Beckman Instruments, Inc., Fullerton, Calif.). Supernates of perchloric acid precipitates of whole blood were prepared immediately and frozen until analyzed for glutamine, acetoacetate, and $\beta$-hydroxybutyrate concentrations (5). Ketone body concentrations were measured within $1 \mathrm{wk}$ of sampling. When stored at $-20^{\circ} \mathrm{C}$ for $7 \mathrm{~d}$, recovery rates for acetoacetate and $\beta$-hydroxybutyrate were $98.4 \pm 5.3$ and $98.0 \pm 3.7 \%$, respectively. For measurement of plasma immunoreactive insulin, $9 \mathrm{vol}$ of plasma were promptly diluted with 1 vol of Trasylol $(5,000 \mathrm{U} / \mathrm{ml}$; FBA Pharmaceuticals, Inc., New York) and frozen until assayed. Serum urea nitrogen was also measured (5).

Throughout the study, daily 24 -h urine specimens were collected in bottles containing thymol as a preservative, refrigerated at $4^{\circ} \mathrm{C}$ during the collection period, and then frozen until analyzed. Urea nitrogen, ammonium, creatinine, uric acid, sodium, and potassium concentrations of each 24 -h urine collections were measured as previously described (5). Urinary total nitrogen was calculated as the sum of urea, creatinine, uric acid, and ammonium nitrogen (5).

Stools were passed infrequently during the fasts, and nitrogen losses by this route were not measured. Statistical analyses were performed using three-way analysis of variance and the paired $t$ test (6).

\section{RESULTS}

Nitrogen excretion. Before beginning the fasts, the average daily urea nitrogen excretion of subjects, who subsequently received 11 or $34 \mathrm{mmol}$ of $\alpha$-ketoisocaproate, $34 \mathrm{mmol}$ of leucíne, or underwent a control fast without infusions was not significantly different.

In Table $I$ are shown mean values of the daily urea nitrogen excretion for days 1-7 and 8-14 of the three fasts of protocol I. Tables II- $\mathrm{V}$ give the individual data: the control fast without infusions and the two fasts when either $34 \mathrm{mmol} / \mathrm{d}$ of $\alpha$-ketoisocaproate or 34 $\mathrm{mmol} / \mathrm{d}$ of leucine were infused on days $1-7$. When these results were analyzed by the technique of analysis of variance, infusions of $\alpha$-ketoisocaproate were associated with significantly lower urea nitrogen excretion compared with the control fast, both for the initial 7-d period of $\alpha$-ketoisocaproate infusion and for the next $7 \mathrm{~d}$ in which no infusions were given. Compared with the fast during which leucine was infused, $\alpha$-ketoisocaproate also resulted in a significantly lower rate of urea nitrogen excretion on days $1-7$ and $8-14$. The difference is also present if the amount of nitrogen contained in the leucine infusions is subtracted from the amount of urea nitrogen excretion. In contrast with the nitrogen-sparing effect of $\alpha$-ketoisocaproate, urinary urea nitrogen excretion rates on days $1-7$ and 8-14 during the leucine infusion fast were not significantly different from those of the control fast, even if the quantity of nitrogen contained in each leucine infusion was subtracted from the daily values for urinary urea nitrogen.

TABLE I

Mean Daily Urinary Urea Nitrogen Excretion during $14 d$ of Fasting: Effects of Infusion of $34 \mathrm{mmol} / \mathrm{d}$ of $\alpha$-Ketoisocaproate or Leucine during the Initial $7 d$

\begin{tabular}{lccc}
\hline \multicolumn{1}{c}{ Study } & Urea nitrogen excretion & $F^{*}$ & $P$ value* \\
\hline & $g / d$ & & \\
Days 1-7 & 6.75 & & \\
$\quad$ No infusion & 5.64 & 15.64 & $<0.001$ \\
$\alpha$-Ketoisocaproate & 6.82 & & \\
$\quad$ Leucine & & & \\
Days 8-14 & 4.61 & & \\
$\quad$ No infusion & 3.77 & 7.25 & $<0.005$ \\
$\quad \alpha$-Ketoisocaproate & 4.50 & & \\
Leucine & & & \\
\hline
\end{tabular}

* Significance determined by analysis of variance between control fasts and fasts during which $\alpha$-ketoisocaproate or leucine was infused. If daily urea nitrogen excretion is reduced by subtracting nitrogen contained within leucine infusions, then mean daily urea nitrogen excretion is 6.42 g/d. This figure remains significantly higher $(F=11.62, P$ $<0.001)$ than mean daily urea nitrogen excretion during $\alpha$-ketoisocaproate infusion. 
TABLE II

Effect of Daily Infusion of $34 \mathrm{mmol} \alpha$-Ketoisocaproate or $34 \mathrm{mmol}$ of Leucine on Days 1-7 of a Fast on Daily Urine Urea Nitrogen Excretion during Days 1-7 of Fasting

\begin{tabular}{|c|c|c|c|c|c|c|c|}
\hline & \multirow[b]{2}{*}{ Day of study } & \multicolumn{6}{|c|}{ Urine urea nitrogen in subject: } \\
\hline & & $\mathbf{A}$ & B & $\mathrm{C}$ & D & $\mathrm{E}$ & F \\
\hline & & \multicolumn{6}{|c|}{ g/d } \\
\hline \multirow[t]{7}{*}{ Control fasts } & 1 & 9.3 & 5.9 & 8.2 & 12.3 & 10.8 & 9.0 \\
\hline & 2 & 8.3 & 5.9 & 5.7 & 8.4 & 11.0 & 5.3 \\
\hline & 3 & 7.3 & 5.5 & 5.1 & 8.0 & 8.2 & 4.4 \\
\hline & 4 & 6.8 & 5.1 & 6.4 & 9.4 & 9.0 & 2.8 \\
\hline & 5 & 6.4 & 4.7 & 7.4 & 7.7 & 8.7 & 2.2 \\
\hline & 6 & 7.0 & 3.9 & 5.5 & 8.1 & 6.9 & 2.9 \\
\hline & 7 & 6.0 & 4.7 & 5.1 & 8.3 & 7.7 & 2.2 \\
\hline \multirow{7}{*}{$\begin{array}{l}\text { Fasts during which } 34 \mathrm{mmol} \text { of } \\
\text { leucine were infused daily }\end{array}$} & 1 & 8.6 & 11.1 & 4.3 & 9.7 & 8.8 & 8.8 \\
\hline & 2 & 9.1 & 7.1 & 5.6 & 9.8 & 9.9 & 4.3 \\
\hline & 3 & 8.3 & 5.8 & 7.6 & 9.6 & 10.0 & 4.2 \\
\hline & 4 & 5.0 & 6.4 & 8.2 & 7.5 & 8.0 & 5.2 \\
\hline & 5 & 4.4 & 5.8 & 6.6 & 8.4 & 6.1 & 5.0 \\
\hline & 6 & 4.9 & 4.8 & 6.3 & 6.5 & 8.0 & 4.9 \\
\hline & 7 & 4.3 & 5.8 & 4.8 & 7.4 & 5.0 & 4.5 \\
\hline \multirow{7}{*}{$\begin{array}{l}\text { Fasts during which } 34 \mathrm{mmol} \text { of } \\
\alpha \text {-ketoisocaproate were } \\
\text { infused daily }\end{array}$} & 1 & 10.5 & 4.1 & 7.4 & 7.2 & 10.0 & 5.9 \\
\hline & 2 & 7.6 & 4.9 & 5.4 & 7.1 & 10.5 & 4.1 \\
\hline & 3 & 6.2 & 4.3 & 5.8 & 7.8 & 10.3 & 1.8 \\
\hline & 4 & 4.6 & 4.0 & 5.7 & 8.0 & 8.9 & 2.0 \\
\hline & 5 & 5.6 & 4.1 & 4.7 & 7.0 & 6.6 & 1.5 \\
\hline & 6 & 4.8 & 2.9 & 4.7 & 5.3 & 6.9 & 1.2 \\
\hline & 7 & 3.4 & 5.1 & 4.3 & 5.8 & 7.3 & 1.6 \\
\hline
\end{tabular}

TABLE III

Effect of Daily Infusion of $34 \mathrm{mmol} \alpha$-Ketoisocaproate or $34 \mathrm{mmol}$ of Leucine on Days 1-7 of a Fast on Daily Urine Urea Nitrogen Excretion during Days 8-14 of Fasting

\begin{tabular}{lcccccc}
\hline & & \multicolumn{5}{c}{ Urine urea nitrogen in subject: } \\
\cline { 3 - 7 } & Day of study & A & B & C & D & E \\
\hline & & & & g/d & & \\
Control fast & 8 & 5.6 & 4.1 & 4.2 & 6.6 & 9.0 \\
& 9 & 3.2 & 3.8 & 3.8 & 5.0 & 5.5 \\
& 10 & 4.1 & 4.7 & 3.3 & 7.8 & 5.4 \\
& 11 & 4.4 & 3.6 & 2.8 & 5.2 & 5.2 \\
& 12 & 2.2 & 4.0 & 2.0 & 4.8 & 5.4 \\
Fasts during which 34 mmol of & 13 & 5.6 & 5.4 & 2.0 & 3.7 & 5.1 \\
leucine were infused daily & 14 & 3.4 & 5.3 & 1.9 & 3.8 & 9.3 \\
& 8 & 4.0 & 4.2 & 5.9 & 5.9 & 6.7 \\
& 9 & 3.8 & 2.4 & 4.1 & 7.0 & 5.0 \\
& 10 & 4.1 & 2.5 & 4.3 & 5.4 & 4.6 \\
& 11 & 5.1 & 2.4 & 4.2 & 6.2 & 6.5 \\
& 12 & 3.2 & 2.6 & 4.3 & 4.7 & 6.2 \\
Fasts during which 34 mmol of & 13 & 5.3 & 2.0 & 3.8 & 3.7 & 6.0 \\
$\alpha$-ketoisocaproate were & 14 & 4.2 & 2.4 & 3.2 & 3.9 & 5.8 \\
infused daily & 8 & 4.9 & 3.0 & 4.3 & 3.9 & 6.3 \\
& 9 & 4.7 & 2.4 & 3.4 & 4.7 & 5.2 \\
& 10 & 4.0 & 3.5 & 3.9 & 3.9 & 5.6 \\
& 11 & 4.5 & 3.3 & 3.4 & 4.4 & 4.1 \\
& 12 & 2.8 & 2.9 & 3.1 & 3.5 & 3.6 \\
& 13 & 2.3 & 2.2 & 3.2 & 4.1 & 4.2 \\
& 14 & 2.7 & 3.9 & 3.1 & 2.8 & 4.2 \\
\hline & & & & & &
\end{tabular}


TABLE IV

Effect of Daily Infusion of $11 \mathrm{mmol} \alpha-$ Ketoisocaproate on Days 1-7 of a Fast on Daily Urine Urea Nitrogen Excretion during Days 1-7 of Fasting

\begin{tabular}{|c|c|c|c|c|c|c|c|c|}
\hline & \multirow[b]{2}{*}{ Day of study } & \multicolumn{7}{|c|}{ Urine urea nitrogen in subject: } \\
\hline & & G & $\mathbf{H}$ & I & $\mathbf{J}$ & $\mathbf{K}$ & $\mathbf{L}$ & $\mathbf{M}$ \\
\hline & & & & & $g / d$ & & & \\
\hline \multirow[t]{7}{*}{ Control fasts } & 1 & 4.0 & 13.8 & 8.2 & 10.3 & 11.6 & 10.8 & 9.2 \\
\hline & 2 & 4.7 & 12.8 & 6.5 & 9.1 & 10.6 & 11.0 & 7.3 \\
\hline & 3 & 4.2 & 16.6 & 7.0 & 6.7 & 8.9 & 8.2 & 6.8 \\
\hline & 4 & 5.7 & 13.8 & 7.2 & 5.0 & 8.9 & 9.0 & 5.9 \\
\hline & 5 & 4.9 & 15.1 & 6.8 & 5.5 & 5.8 & 8.7 & 6.2 \\
\hline & 6 & 4.0 & 14.8 & 6.5 & 5.8 & 4.0 & 6.9 & 5.0 \\
\hline & 7 & 3.4 & 11.6 & 6.5 & 9.8 & 3.8 & 7.7 & 4.8 \\
\hline \multirow{7}{*}{$\begin{array}{l}\text { Fasts during which } 11 \mathrm{mmol} \text { of } \\
\alpha \text {-ketoisocaproate were } \\
\text { infused daily }\end{array}$} & 1 & 5.9 & 8.7 & 10.3 & 9.6 & 7.4 & 9.1 & 9.6 \\
\hline & 2 & 5.9 & 6.9 & 6.8 & 7.5 & 7.7 & 8.3 & 9.5 \\
\hline & 3 & 7.5 & 11.7 & 8.2 & 5.1 & 7.7 & 8.4 & 6.6 \\
\hline & 4 & 6.0 & 11.9 & 7.4 & 5.3 & 6.1 & 9.0 & 5.5 \\
\hline & 5 & 5.9 & 10.3 & 6.5 & 7.1 & 5.4 & 6.8 & 4.6 \\
\hline & 6 & 2.8 & 9.2 & 5.7 & 6.5 & 5.5 & 6.1 & 5.0 \\
\hline & 7 & 3.2 & 6.2 & 6.5 & 3.7 & 7.0 & 6.1 & 5.3 \\
\hline
\end{tabular}

The average urea nitrogen excretion for each day of the three studies is graphically displayed in Figs. 1 and 2 . In Fig. 1 is shown a comparison of daily urinary urea nitrogen during the control fast and the fast when $\alpha$ ketoisocaproate was infused. Urea nitrogen excretion was lower during 13 of $14 \mathrm{~d}$ of the infusion study. Similar results were found when the study with leucine infusions was compared with the study with $\alpha$-ketoisocaproate infusions (Fig. 2). Urea nitrogen excretion was lower during all $14 \mathrm{~d}$ of the $\alpha$-ketoisocaproate study.

Infusion of $11 \mathrm{mmol} / \mathrm{d}$ of $\alpha$-ketoisocaproate on days 1-7 of a 14-d fast (protocol II) also significantly lowered mean daily urine urea nitrogen excretion compared with the control fast without infusions. Again, the lower urea nitrogen excretion was observed during the week of infusions and for the next week when no infusions were administered (Table VI).

TABLE V

Effect of Daily Infusion of $11 \mathrm{mmol} \alpha$-Ketoisocaproate on Days 1-7 of a Fast on Daily Urine Urea Nitrogen Excretion during Days 8-14 of Fasting

\begin{tabular}{|c|c|c|c|c|c|c|c|}
\hline & \multirow[b]{2}{*}{ Day of study } & \multicolumn{6}{|c|}{ Urine urea nitrogen in subject: } \\
\hline & & G & $\mathbf{H}$ & I & $\mathbf{J}$ & $\mathbf{K}$ & $\mathrm{L}$ \\
\hline & & & & $g /$ & & & \\
\hline \multirow[t]{7}{*}{ Control fast } & 8 & 4.3 & 9.0 & 7.1 & 5.1 & 3.5 & 9.0 \\
\hline & 9 & 4.2 & 10.2 & 5.2 & 4.1 & 3.0 & 5.5 \\
\hline & 10 & 3.3 & 13.0 & 4.6 & 4.0 & 2.7 & 5.4 \\
\hline & 11 & 3.7 & 8.8 & 4.3 & 4.5 & 2.8 & 5.2 \\
\hline & 12 & 4.3 & 8.4 & 4.0 & 3.4 & 2.3 & 5.4 \\
\hline & 13 & 2.9 & 6.7 & 4.2 & 1.9 & 2.6 & 5.1 \\
\hline & 14 & 3.5 & 6.8 & 3.7 & 2.8 & 2.3 & 9.3 \\
\hline \multirow{7}{*}{$\begin{array}{l}\text { Fasts during which } 11 \mathrm{mmol} \text { of } \\
\alpha \text {-ketoisocaproate were } \\
\text { infused daily }\end{array}$} & 8 & 3.7 & 4.1 & 7.1 & 4.2 & 4.7 & 5.2 \\
\hline & 9 & 2.4 & 7.8 & 6.0 & 4.8 & 4.5 & 4.3 \\
\hline & 10 & 2.7 & 6.0 & 5.7 & 2.6 & 5.3 & 4.8 \\
\hline & 11 & 1.1 & 7.1 & 5.1 & 3.7 & 2.6 & 4.3 \\
\hline & 12 & 2.0 & 6.6 & 3.6 & 2.9 & 2.2 & 3.8 \\
\hline & 13 & 1.8 & 6.7 & 4.0 & 2.1 & 2.2 & 4.2 \\
\hline & 14 & 2.5 & 5.4 & 4.1 & 2.1 & 1.8 & 6.9 \\
\hline
\end{tabular}




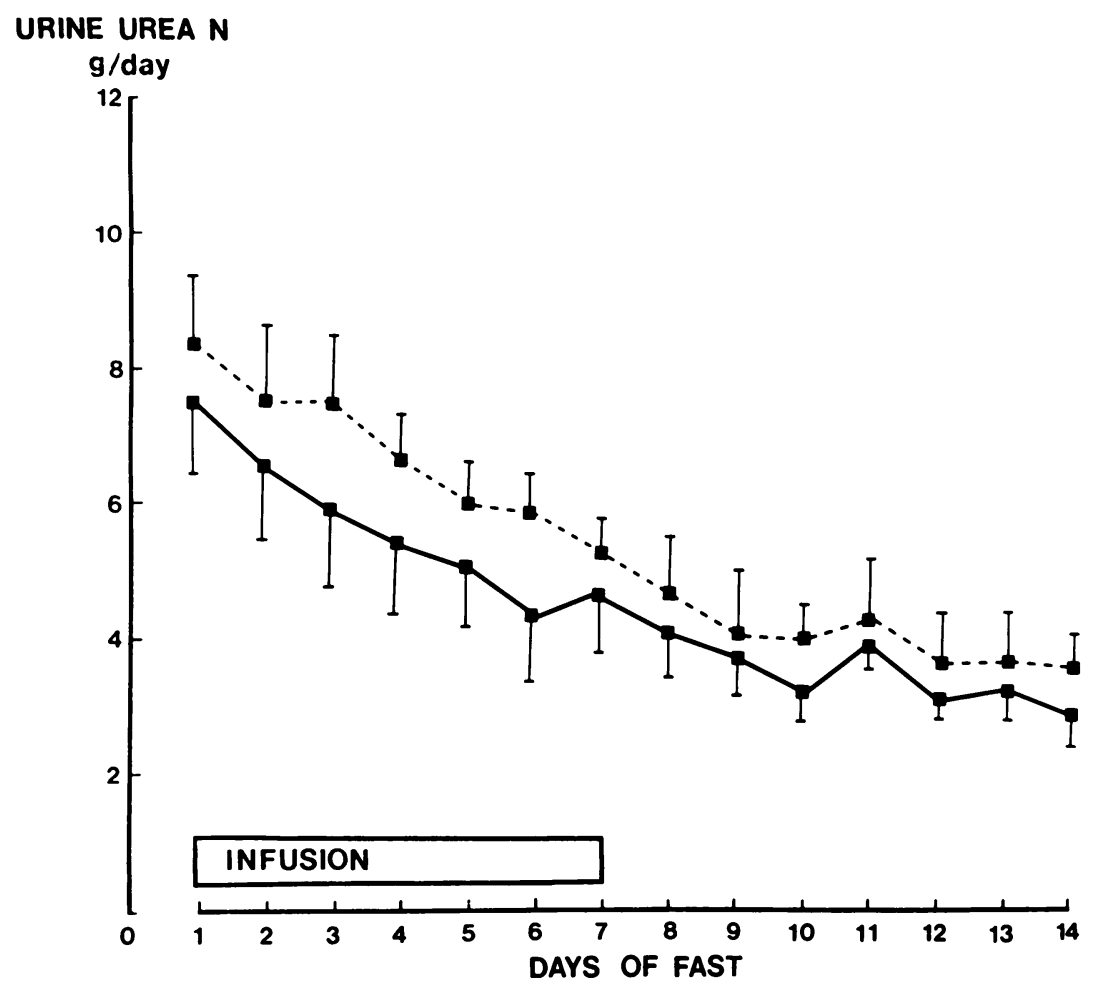

FIGURE 1 The effects of infusing $34 \mathrm{mmol} \alpha$-ketoisocaproate (-) daily during the first $7 \mathrm{~d}$ of a fast on daily urinary urea nitrogen excretion compared with daily urinary urea nitrogen excretion during a control fast (- - ). The vertical bars represent \pm SEM.

Urea nitrogen excretion values for each day of the studies of protocol II are graphically displayed in Fig. 3. Compared with a control fast, urea nitrogen excretion was lower for all $14 \mathrm{~d}$ of the infusion study.

Total urinary nitrogen excretion was estimated as the sum of daily excretion of creatinine, uric acid, ammonium, and urea nitrogen. The sum of creatinine, uric acid, and ammonium did not differ significantly between the three fasts of protocol I and the two fasts of protocol II when the data were analyzed by analysis of variance. Thus, the differences found in estimated total urinary nitrogen excretion were a result of urea nitrogen excretion. The nitrogen-sparing effects of infusing 11 or $34 \mathrm{mmol}$ of $\alpha$-ketoisocaproate were similar, and averaged approximately $1 \mathrm{~g} / \mathrm{d}$ over the entire 14-d study.

Plasma amino acids. The changes in plasma amino acid concentrations during control fasts of protocols I and II were similar to those described by Felig et al. (7).

Plasma amino acid concentrations of the six patients measured during protocol I studies were compared in the following ways. (a) Plasma amino acid values measured on day 1 before the first infusion of $34 \mathrm{mmol}$ of $\alpha$-ketoisocaproate or $34 \mathrm{mmol}$ of leucine were compared (Table VII): there were no significant differences in any of the amino acid concentrations. (b) On days 1 and 7 , the percent changes from preinfusion values of plasma amino acid concentrations measured $1 \mathrm{~h}$ after infusion of $34 \mathrm{mmol}$ of $\alpha$-ketoisocaproate and $34 \mathrm{mmol}$ of leucine were compared (Table VII): $1 \mathrm{~h}$ after infusion of $34 \mathrm{mmol}$ of $\alpha$-ketoisocaproate, the average plasma leucine concentration increased 61 and $69 \%$ on days 1 and 7 , respectively. On days 1 and 7 , infusion of 34 mmol of $\alpha$-ketoisocaproate as well as infusion of 34 mmol of leucine significantly reduced the total concentration of plasma amino acids (Table VII). The decrease in total amino acid concentration $1 \mathrm{~h}$ after infusion of $34 \mathrm{mmol}$ of leucine and $34 \mathrm{mmol}$ of $\alpha$-ketoisocaproate was not different on day $1(-12 \%$ leucine, $-16 \% \alpha$-ketoisocaproate) or on day 7 ( $-6 \%$ leucine, $-9 \% \alpha$-ketoisocaproate). Significant decreases in many individual amino acid concentrations were observed after infusion of $\alpha$-ketoisocaproate or leucine (Table VII). (c) Preinfusion plasma amino acid concentrations on day 7 of studies in which $\alpha$-ketoisocaproate or leucine was administered were compared with each other. The same comparisons were made from values obtained on the morning of the last study day. When $\alpha$-ketoisocaproate and leucine infusions were compared, there were no significant differences in plasma amino acid concentrations on day 7 or on the morning after the last study day, except for a lower plasma gly- 


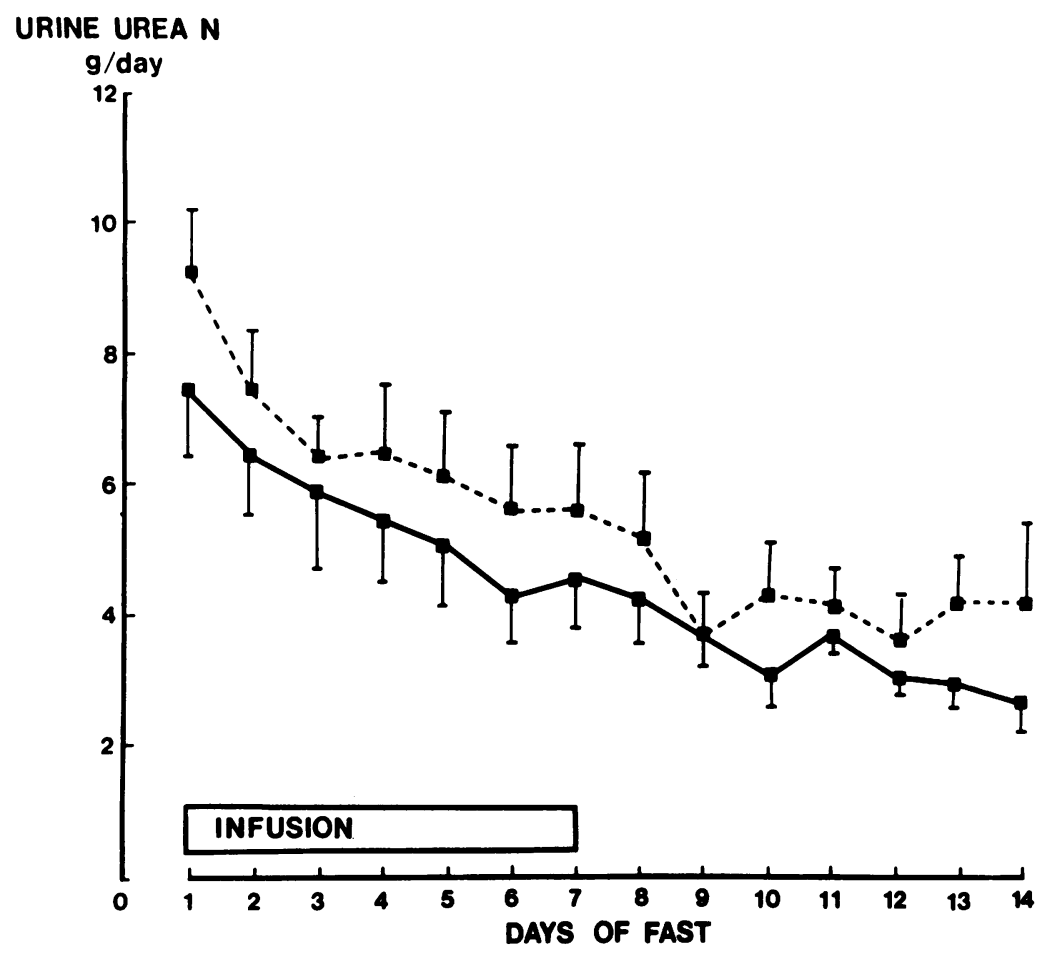

FIGURE 2 The effects of infusing $34 \mathrm{mmol}$ leucine $(---)$ or $34 \mathrm{mmol} \alpha$-ketoisocaproate $(-)$ daily during the first $7 \mathrm{~d}$ of a fast on daily urinary urea nitrogen excretion. The vertical bars represent \pm 1 SEM.

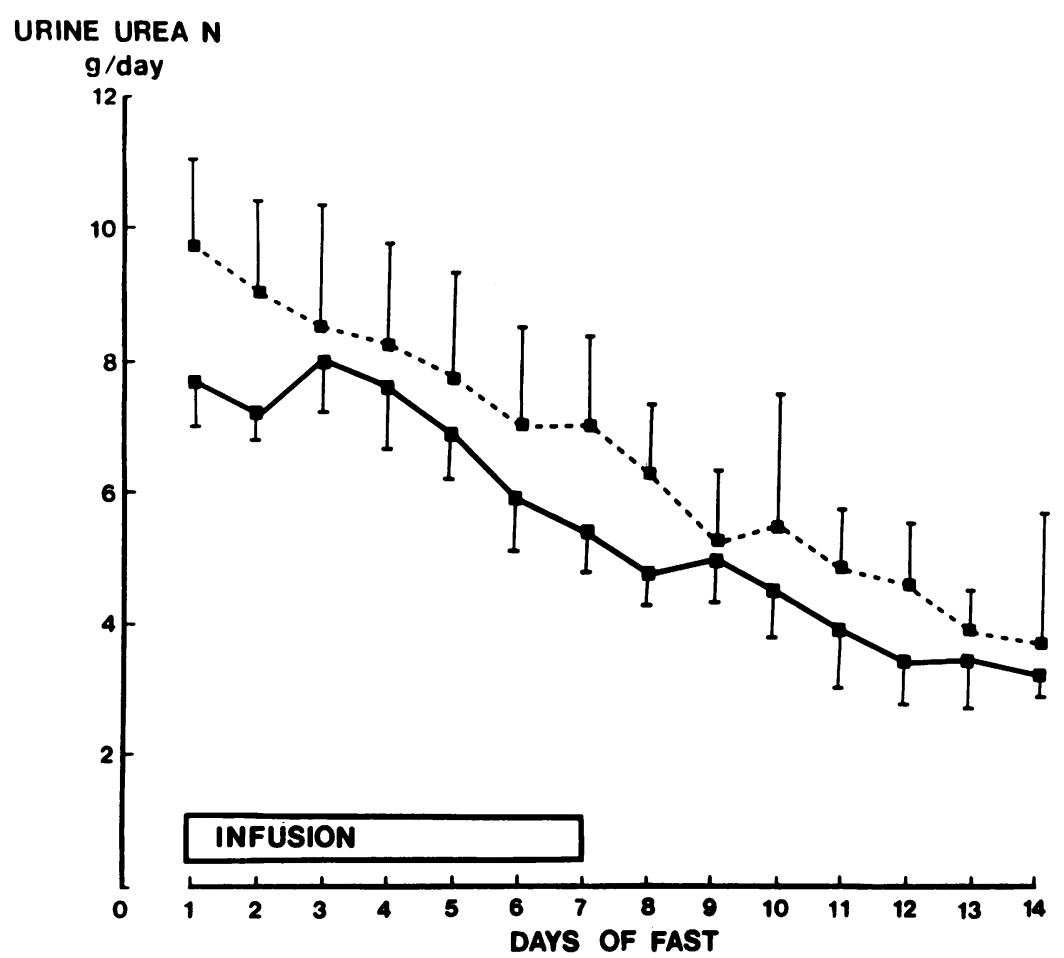

Figure 3 The effects of infusing $11 \mathrm{mmol} \alpha$-ketoisocaproate $(-)$ daily during the first $7 \mathrm{~d}$ of a fast on daily urinary urea nitrogen excretion compared with daily urinary urea nitrogen excretion during a control fast (-- ). The vertical bars represent \pm 1 SEM. 
TABLE VI

Mean Daily Urea Nitrogen Excretion during 14 Days of Fasting: Effects of Infusion of $11 \mathrm{mmol} / \mathrm{d}$ of $\alpha$-Ketoisocaproate Compared with a Fast without Infusion

\begin{tabular}{lccc}
\hline \multicolumn{1}{c}{ Study } & Urea nitrogen excretion & $F^{*}$ & $P$ value $^{*}$ \\
\hline Days 1-7 & $g / d$ & & \\
$\quad$ No infusion & 8.00 & & \\
$\quad \alpha$-Ketoisocaproate & 7.04 & 22 & $<0.001$ \\
$\begin{array}{l}\text { Days 8-14 } \\
\quad \text { No infusion }\end{array}$ & 5.05 & & \\
$\alpha$-Ketoisocaproate & 4.16 & 16.37 & $<0.001$ \\
\end{tabular}

* Significance value calculated by analysis of variance between the fasts without infusion and the fast during which $\alpha$-ketoisocaproate was infused. cine concentration $(P<0.025)$ on day 7 of the study in which $\alpha$-ketoisocaproate was infused. $(d)$ Values obtained before infusion of $\alpha$-ketoisocaproate or leucine on day 7 and values obtained on day 15 of these studies were compared with values obtained on the morning of days 7 and 15 of the control fast. Compared with values obtained on day 7 of the control study, on the morning of the last day of infusion of $34 \mathrm{mmol}$ of $\alpha$-ketoisocaproate plasma threonine was lower $(-34 \pm 12 \mu \mathrm{M}$, $P<0.05)$, and plasma alloisoleucine was higher $(+17$ $\pm 4 \mu \mathrm{M}, P<0.025$ ). Comparison of plasma amino acid concentrations on day 15 of control and infusion fasts showed few differences. $\alpha$-Ketoisocaproate infusion was associated with a decrease in cystine $(-21 \pm 7 \mu \mathrm{M})$ and lysine $(-24 \pm 8 \mu \mathrm{M}), P<0.05$, compared to control. Leucine infusion was associated with a decrease in

TABLE VII

Plasma Amino Acid Concentration Measured on Day 1 and Day 7 of a Fast before and 1 h after Infusion of $34 \mathrm{mmol}$ of $\alpha$-Ketoisocaproate or $34 \mathrm{mmol}$ of Leucine

\begin{tabular}{|c|c|c|c|c|c|c|c|c|}
\hline & \multicolumn{4}{|c|}{$34 \mathrm{~mm} \alpha$-ketoisocaproate } & \multicolumn{4}{|c|}{$34 \mathrm{mmol}$ leucine } \\
\hline & \multicolumn{2}{|c|}{ Day 1} & \multicolumn{2}{|c|}{ Day 7} & \multicolumn{2}{|c|}{ Day 1} & \multicolumn{2}{|c|}{ Day 7} \\
\hline & Pre & $\begin{array}{l}\text { change } \\
1 \text { h post }\end{array}$ & Pre & $\begin{array}{l}\text { change } \\
1 \mathrm{~h} \text { post }\end{array}$ & Pre & $\begin{array}{l}\text { change } \\
1 \text { h post }\end{array}$ & Pre & $\begin{array}{l}\text { change } \\
1 \mathrm{~h} \text { post }\end{array}$ \\
\hline & \multicolumn{8}{|c|}{$\mu M$} \\
\hline Taurine & $75 \pm 8$ & $-27 \pm 13$ & $68 \pm 11$ & $-22 \pm 6$ & $66 \pm 5$ & $-15 \pm 7$ & $67 \pm 10$ & $-6 \pm 17$ \\
\hline Aspartate & $7 \pm 2$ & $-2 \pm 2$ & $4 \pm 4$ & $-1 \pm 1$ & $5 \pm 1$ & $-1 \pm 1$ & $4 \pm 1$ & 0 \\
\hline Threonine & $149 \pm 29$ & $-35 \pm 11 \ddagger$ & $132 \pm 16$ & $-10 \pm 2 \S$ & $160 \pm 28$ & $-56 \pm 15$ & $138 \pm 18$ & $-22 \pm 5 \S$ \\
\hline Serine & $118 \pm 17$ & $-25 \pm 9 \pi$ & $104 \pm 7$ & $-12 \pm 2 \S$ & $102 \pm 8$ & $-15 \pm 2$ & $101 \pm 7$ & $-19 \pm 4 \S$ \\
\hline Asparagine & $37 \pm 3$ & $-8 \pm 7$ & $51 \pm 9$ & $-2 \pm 6$ & $44 \pm 4$ & $-10 \pm 1^{\prime \prime}$ & $45 \pm 6$ & $-3 \pm 2$ \\
\hline Glutamate & $70 \pm 8$ & $-25 \pm 6 \S$ & $43 \pm 7$ & $-13 \pm 3 \S$ & $55 \pm 5$ & $-3 \pm 6$ & $42 \pm 4$ & $-9 \pm 5$ \\
\hline Glutamine* & $428 \pm 97$ & $-44 \pm 28$ & $396 \pm 100$ & $-107 \pm 108$ & $506 \pm 95$ & $-41 \pm 82$ & $556 \pm 140$ & $-53 \pm 61$ \\
\hline Proline & $180 \pm 12$ & $-45 \pm 7 \S$ & $178 \pm 18$ & $-22 \pm 79$ & $192 \pm 27$ & $-44 \pm 13 \ddagger$ & $172 \pm 6$ & $-30 \pm 7 \S$ \\
\hline Glycine & $202 \pm 26$ & $-33 \pm 13$ & $226 \pm 29$ & $-16 \pm 6$ & $199 \pm 17$ & $-27 \pm 5 \S$ & $218 \pm 31$ & $-25 \pm 3^{\prime \prime}$ \\
\hline Alanine & $321 \pm 42$ & $-61 \pm 28$ & $225 \pm 32$ & $-36 \pm 37$ & $348 \pm 35$ & $-79 \pm 14 \S$ & $240 \pm 34$ & $-59 \pm 26$ \\
\hline Citrulline & $29 \pm 2$ & $-6 \pm 1$ & $19 \pm 2$ & $-1 \pm 2$ & $37 \pm 4$ & $-9 \pm 4$ & $20 \pm 1$ & $+1 \pm 2$ \\
\hline Valine & $243 \pm 19$ & $-85 \pm 12^{\prime \prime}$ & $285 \pm 24$ & $-76 \pm 6^{\prime \prime}$ & $296 \pm 23$ & $-135 \pm 13^{\prime \prime}$ & $309 \pm 33$ & $-88 \pm 12 \S$ \\
\hline Cystine & $171 \pm 9$ & $-17 \pm 10$ & $154 \pm 8$ & $-16 \pm 7$ & $155 \pm 11$ & $-11 \pm 2 \S$ & $147 \pm 16$ & $-17 \pm 6$ \\
\hline Methionine & $24 \pm 1$ & $-6 \pm 2$ & $26 \pm 2$ & $-5 \pm 1 \S$ & $27 \pm 3$ & $-9 \pm 2$ & $26 \pm 2$ & $-8 \pm 4^{\prime \prime}$ \\
\hline Alloisoleucine & $6 \pm 1$ & $+14 \pm 4 \ddagger$ & $27 \pm 5$ & $+14 \pm 3 \S$ & $6 \pm 1$ & $-1 \pm 1$ & $6 \pm 1$ & $-1 \pm 1$ \\
\hline Isoleucine & $68 \pm 5$ & $-34 \pm 5 \S$ & $117 \pm 10$ & $-36 \pm 3^{\prime \prime}$ & $83 \pm 6$ & $-54 \pm 6^{\prime \prime}$ & $114 \pm 7$ & $-48 \pm 3^{\prime \prime}$ \\
\hline Leucine & $127 \pm 9$ & $+78 \pm 10^{\prime \prime}$ & $221 \pm 16$ & $+152 \pm 12$ & $150 \pm 8$ & $+241 \pm 75 t$ & $238 \pm 20$ & $+281 \pm 36 \S$ \\
\hline Tyrosine & $79 \pm 7$ & $-19 \pm 79$ & $62 \pm 4$ & $-13 \pm 2$ & $82 \pm 7$ & $-28 \pm 49$ & $66 \pm 7$ & $-16 \pm 5 t$ \\
\hline Phenylalanine & $55 \pm 4$ & $-15 \pm 6$ & $54 \pm 2$ & $-11 \pm 2 \S$ & $63 \pm 4$ & $-21 \pm 2$ & $55 \pm 4$ & $-13 \pm 3 \ddagger$ \\
\hline Ornithine & $78 \pm 11$ & $-15 \pm 4 t$ & $60 \pm 7$ & $+2 \pm 4$ & $76 \pm 8$ & $-10 \pm 4$ & $63 \pm 3$ & $-3 \pm 3$ \\
\hline Lysine & $202 \pm 17$ & $-24 \pm 14$ & $172 \pm 16$ & $-5 \pm 2$ & $215 \pm 10$ & $-24 \pm 9$ & $185 \pm 15$ & $-13 \pm 8$ \\
\hline Histidine & $83 \pm 6$ & $-12 \pm 49$ & $71 \pm 6$ & $-5 \pm 1$ & $87 \pm 8$ & $-16 \pm 3 \S$ & $78 \pm 8$ & $-10 \pm 2 \S$ \\
\hline Arginine & $79 \pm 7$ & $-11 \pm 4 \rrbracket$ & $67 \pm 9$ & $-6 \pm 4$ & $81 \pm 5$ & $-6 \pm 3$ & $63 \pm 5$ & $-2 \pm 4$ \\
\hline $\begin{array}{l}\text { Total measured } \\
\text { amino acids }\end{array}$ & 2,381 & -457 & 2,761 & $-247 \ddagger$ & 3.035 & -365 & 2,953 & $-163^{\prime \prime}$ \\
\hline
\end{tabular}

* Glutamine was measured enzymatically in whole blood.

$\neq P<0.025$.

$\S P<0.01$.

" $P<0.001$.

II $P<0.05$. 
serine $(-31 \pm 11 \mu \mathrm{M})$ and cystine $(-18 \pm 6 \mu \mathrm{M})$ concentrations, $P<0.05$ compared with control.

Comparison of plasma amino acid concentrations during protocol II studies was also carried out in several ways: Plasma amino acid values prior to infusion (day 1 and day 7) were compared with values obtained $1 \mathrm{~h}$ after infusion of $11 \mathrm{mmol}$ of $\alpha$-ketoisocaproate. $\alpha$-Ketoisocaproate resulted in a 9 and $7 \%$ decrease in total plasma amino acids on days 1 and 7 , respectively.

$1 \mathrm{~h}$ after infusion of $11 \mathrm{mmol} \alpha$-ketoisocaproate, plasma leucine concentration increased on days 1 and 7 by 32 and $21 \%$ respectively, whereas the concentrations of a number of individual amino acids decreased (Table VIII). Plasma amino acid concentrations obtained on day 7 and the last day of the control fast were compared with values obtained before infusion of $\alpha$-ketoisocaproate (day 7 ) and $1 \mathrm{wk}$ after infusions were discontinued. On day 7 , the infusions of $\alpha$-ketoisocaproate were associated with a lower valine $(-70 \pm 16 \mu \mathrm{M}$, $P<0.01)$ and taurine $(-35 \pm 11 \mu \mathrm{M}, P<0.025)$ concentration compared with control studies.

Blood acetoacetate and $\beta$-hydroxybutyrate concentrations. $1 \mathrm{~h}$ after the infusion of $34 \mathrm{mmol}$ of $\alpha$ ketoisocaproate, blood acetoacetate $(0.048 \pm 0.021 \mu \mathrm{M})$ and $\beta$-hydroxybutyrate $(0.089 \pm 0.035 \mu \mathrm{M})$ rose on days 1 and 7 . Leucine infusion caused similar changes (acetoacetate, $0.029 \pm 0.010 \mu \mathrm{M} ; \beta$-hydroxybutyrate, 0.082 $\pm 0.010 \mu \mathrm{M})$.

$1 \mathrm{~h}$ after the infusion of $11 \mathrm{mmol}$ of $\alpha$-ketoisocaproate (protocol II), blood acetoacetate $(0.077 \pm 0.023 \mu \mathrm{M})$ and $\beta$-hydroxybutyrate $(0.281 \pm 0.079 \mu \mathrm{M})$ were increased, compared with preinfusion values, both on days 1 and 7. Values for ketone bodies in blood samples drawn at 8:00 A.M. on days 7 and 15 did not differ significantly between groups of patients or treatments.

Insulin and $p H$. Plasma insulin concentration was not significantly increased $1 \mathrm{~h}$ after infusion of 11 or $34 \mathrm{mmol}$ of $\alpha$-ketoisocaproate or $34 \mathrm{mmol}$ of leucine. The mean plasma insulin concentration on days 7 and 15 of control fasts $(13 \pm 3$ and $18 \pm 6 \mathrm{U} / \mathrm{ml})$ was not significantly different from that measured on days 7 and 15 before the infusions in protocols I and II.

There were no significant changes in venous $\mathrm{pH}$ or calculated plasma bicarbonate concentration measured $1 \mathrm{~h}$ after infusion of $\alpha$-ketoisocaproate or leucine. Similarly, there were no differences in these acid-base parameters when values from days 7 and 15 of infusion fasts were compared with values obtained during the respective control fasts (protocols I and II).

Urine volume, sodium excretion, and weight loss. There were no significant differences in daily urine volume or cumulative sodium excretion between the infusion fasts and control fasts of protocol I studies. There were no significant differences in mean cumulative weight loss during control $(-11.2 \pm 1.0 \mathrm{~kg})$ fasts or fasts when $34 \mathrm{mmol} \alpha$-ketoisocaproate $(-12.4 \pm 1.1 \mathrm{~kg})$ were infused, or when $34 \mathrm{mmol}$ of leucine were infused $(-12.7 \pm 1.1 \mathrm{~kg})$.
TABLE VIII

Plasma Amino Acid Concentrations Measured on Day 1 and Day 7 of Fast, before and $1 \mathrm{~h}$ after Infusion of $11 \mathrm{mmol}$ of $\alpha$-Ketoisocaproate

\begin{tabular}{|c|c|c|c|c|}
\hline \multirow[b]{2}{*}{ Amino acid } & \multicolumn{2}{|c|}{ Day 1} & \multicolumn{2}{|c|}{ Day 7} \\
\hline & Pre & $\begin{array}{l}\text { change } \\
1 \mathrm{~h} \text { post }\end{array}$ & Pre & $\begin{array}{l}\text { change } \\
1 \text { h post }\end{array}$ \\
\hline & \multicolumn{4}{|c|}{$\mu M$} \\
\hline Taurine & $82 \pm 17$ & $-8 \pm 4$ & $72 \pm 12$ & $-13 \pm 4 \ddagger$ \\
\hline Aspartate & $5 \pm 1$ & $-4 \pm 3$ & $3 \pm 0$ & $0 \pm 0$ \\
\hline Threonine & $169 \pm 13$ & $-23 \pm 4 \S$ & $171 \pm 17$ & $-7 \pm 8$ \\
\hline Serine & $133 \pm 18$ & $-18 \pm 5$ & $117 \pm 11$ & $-3 \pm 3$ \\
\hline Asparagine & $35 \pm 4$ & $-4 \pm 3$ & $43 \pm 4$ & $+1 \pm 4$ \\
\hline Glutamate & $138 \pm 33$ & $-7 \pm 17$ & $66 \pm 15$ & $+5 \pm 14$ \\
\hline Glutamine* & $420 \pm 47$ & $-22 \pm 39$ & $278 \pm 18$ & $+11 \pm 34$ \\
\hline Proline & $213 \pm 17$ & $-21 \pm 9$ & $232 \pm 14$ & $+4 \pm 7$ \\
\hline Glycine & $224 \pm 16$ & $-14 \pm 9$ & $285 \pm 33$ & $-3 \pm 12$ \\
\hline Alanine & $359 \pm 30$ & $-45 \pm 25$ & $289 \pm 43$ & $-59 \pm 13 \S$ \\
\hline Citrulline & $31 \pm 2$ & $-3 \pm 2$ & $21 \pm 1$ & $0 \pm 0$ \\
\hline Valine & $290 \pm 30$ & $-75 \pm 7$ & $392 \pm 32$ & $-60 \pm 199$ \\
\hline Cystine & $152 \pm 11$ & $-3 \pm 4$ & $150 \pm 18$ & $-4 \pm 2$ \\
\hline Methionine & $29 \pm 1$ & $-7 \pm 2 \ddagger$ & $33 \pm 1$ & $-6 \pm 1 \S$ \\
\hline \multicolumn{5}{|l|}{ Alloiso- } \\
\hline leucine & $5 \pm 2$ & $+1 \pm 1$ & $11 \pm 3$ & $0 \pm 0$ \\
\hline Isoleucine & $84 \pm 11$ & $-32 \pm 5 \S$ & $145 \pm 13$ & $-36 \pm 8 \ddagger$ \\
\hline Leucine & $174 \pm 24$ & $+55 \pm 16$ & $295 \pm 35$ & $+62 \pm 19 \neq$ \\
\hline Tyrosine & $76 \pm 4$ & $-15 \pm 2^{\prime \prime}$ & $75 \pm 3$ & $-13 \pm 2 \S$ \\
\hline \multicolumn{5}{|l|}{ Phenyl- } \\
\hline alanine & $63 \pm 3$ & $-13 \pm 3 \ddagger$ & $66 \pm 5$ & $-6 \pm 2 \uparrow$ \\
\hline Ornithine & $70 \pm 8$ & $0 \pm 0$ & $60 \pm 3$ & $-2 \pm 2$ \\
\hline Lysine & $211 \pm 9$ & $-8 \pm 8$ & $210 \pm 13$ & $-21 \pm 12$ \\
\hline Histidine & $77 \pm 5$ & $-3 \pm 3$ & $73 \pm 5$ & $-8 \pm 5$ \\
\hline Arginine & $86 \pm 6$ & $-3 \pm 3$ & $83 \pm 3$ & $-11 \pm 5$ \\
\hline \multirow{2}{*}{\multicolumn{5}{|c|}{$\begin{array}{l}\text { Total } \\
\text { measured } \\
\text { amino }\end{array}$}} \\
\hline & & & & \\
\hline acids & 3,091 & $-272 \ddagger$ & 3,170 & -169 \\
\hline
\end{tabular}

* Glutamine measured enzymatically in whole blood.

$\ddagger P<0.025$.

$\$ P<0.01$.

" $P<0.001$.

I $P<0.05$.

\section{DISCUSSION}

Several tissues, including skeletal muscle, gut, liver, and kidney can interconvert $\alpha$-keto analogues of branched-chain amino acids and their respective amino acids (8-10). Because of this interconversion, it is difficult to ascribe biological effects to either branchedchain amino acids or their $\alpha$-keto analogues after administration of one or the other compound. In the present study, we attempted to address this problem by studying the effects of leucine and $\alpha$-ketoisocaproate in the same patients. The results indicate that the effect of administration of $\boldsymbol{\alpha}$-ketoisocaproate in fasting subjects is different from the effects of administering leucine, even though leucine must have been metabolized to 
$\alpha$-ketoisocaproate. We found that intravenous infusion of $\alpha$-ketoisocaproate reduces urea nitrogen and calculated total nitrogen excretion of obese subjects undergoing starvation. This phenomenon was not observed when leucine was infused in the same subjects. Total urinary nitrogen excretion during infusion of leucine was insignificantly different from control values even if nitrogen contained in the infused leucine were subtracted from the amount of nitrogen excreted. It should be emphasized that these experiments were carried out in fasting obese subjects, and different results may have been obtained in fasting nonobese subjects.

During the early phase of starvation, when glucose is a prime energy source, release of amino acids from skeletal muscle is increased to provide gluconeogenic substrates. Later in starvation, muscle amino acid release decreases as ketone bodies and fatty acids become the major energy source (11). From these considerations, a likely site of the observed effects of $\alpha$-ketoisocaproate on urine urea nitrogen excretion during the early phase of starvation is skeletal muscle. Furthermore, $\alpha$-ketoisocaproate does not affect ureagenesis in isolated hepatocytes (12).

After addition of leucine, alanine release from the muscle is increased, presumably as a result of transamination of pyruvate (13). Infusion of $\alpha$-ketoisocaproate decreases alanine release from the muscle, probably by diverting nitrogen from amination of pyruvate. However, the decrease in alanine release in isolated perfused muscle is less than the increment in leucine release, at least in certain experimental models (8). Thus, it is difficult to assign the effect of $\alpha$-ketoisocaproate on urea nitrogen excretion entirely to diminished output of alanine from muscle. Furthermore, we found no differences in circulating levels of alanine when either $\alpha$-ketoisocaproate or leucine was infused. Likewise, Sherwin (4) found either no change or a decrease in plasma alanine after infusion of leucine. Thus, plasma alanine concentration may not reflect changes in the release of this amino acid from the periphery. Moreover, we cannot attribute our findings to a decrease in circulating total $\alpha$-amino nitrogen, because this quantity fell by a similar amount after infusion of either leucine or $\alpha$-ketoisocaproate.

Recently it was reported that during infusion of $\alpha$ ketoisocaproate into forearm muscle of normal subjects fasted overnight, there was no detectable change in arteriovenous difference of tyrosine, phenylalanine, lysine, or total $\alpha$-amino nitrogen (14), suggesting that $\alpha$-ketoisocaproate had no anabolic effect in muscle. These results might suggest that the effect of $\alpha$-ketoisocaproate we have observed involves an organ other than skeletal muscle. However, the results obtained by Pozefsky and Walser (14) may not apply in the analysis of our findings. In the forearm perfusion study, subjects were fasted overnight, and the duration of the infusion was only $30 \mathrm{~min}$. Furthermore, small changes in amino acid flux that would suggest changes in muscle nitrogen balance may have been obscured by errors in blood flow measurement.

As cited previously, branched-chain amino acids, and specifically leucine, increase the protein synthesis rate of isolated, incubated rat diaphragm muscle $(1,2)$. Furthermore, Fulks et al. (1) have shown that leucine decreased the rate of catabolism in these muscles. Chang and Goldberg (15) reported that addition of $\alpha$-ketoisocaproate to incubated skeletal muscle obtained from fasted rats reduced oxidation of pyruvate and accelerated its release from muscle, as well as release of lactate. Inasmuch as lactate and pyruvate are major substrates for gluconeogenesis during early phases of fasting (16), possible acceleration of their cellular release by $\alpha$-ketoisocaproate infusions could reduce gluconeogenesis from amino acids and thereby diminish nitrogen wasting. Recently, Tischler and Goldberg (17) showed that whereas leucine itself accelerated protein synthesis in incubated rat skeletal muscle, reduction of protein degradation rate was a property of $\alpha$-ketoisocaproate, not leucine. Even though leucine is metabolized to $\alpha$-ketoisocaproate, Chang and Goldberg (15) have shown that the biological effects of $\alpha$-ketoisocaproate may be greater after blocking its interconversion with leucine. Thus, the nitrogen-sparing effects of $\alpha$ ketoisocaproate may be dependent upon the rate at which this compound, or its metabolites, achieves a critical concentration within cells.

Our findings contrast with those reported by Sherwin (4), who found that total urinary nitrogen excretion of fasting subjects was reduced by infusion of leucine. He reported that nitrogen excretion was decreased on day 3 of a fast when $75 \mu \mathrm{mol} / \mathrm{min}$ per $\mathrm{M}^{2}$ of leucine was infused over $12 \mathrm{~h}$, compared with urinary nitrogen excretion on the next day. We infused approximately onethird of this amount of leucine on a daily basis and a total of about 2.5 times this much over $1 \mathrm{wk}$ and observed no difference in urinary nitrogen excretion on days 1-7 or 8-14 compared with urinary nitrogen excretion during a control fasting study. In contrast, infusion of an equivalent amount of $\alpha$-ketoisocaproate reduced urinary nitrogen excretion on days $1-7$ and 8-14 (Table I and Figs. 1 and 2). Sherwin (4) also found that leucine reduced urinary nitrogen excretion after 4 wk of starvation.

Interpretation of the nitrogen balance data of Sherwin (4) is complicated for the following reasons. During the infusion on day 3 , nitrogen excretion decreased by approximately the same amount as it had on day 2 . During the day after the infusion, urinary nitrogen excretion increased by approximately the same amount that had previously been infused as leucine $(2.6 \mathrm{~g})$. On the 5 th $\mathrm{d}$ of starvation, $2 \mathrm{~d}$ after leucine infusion, urinary nitrogen excretion was indistinguishable from that measured on days 2 or 4. As shown in Figs. 1 and 2, and previously reported by Owen et al. (18) urinary nitrogen excretion on days 4 and 5 of a fast (without 
infusions) is lower than urinary nitrogen excretion on day 2 . It may be that the nitrogen contained in leucine infused on day 3 was excreted on the two subsequent days of fasting.

In the report by Sherwin (4), leucine infusion was not accompanied by a decrease in urinary creatinine or 3methylhistidine excretion, but was associated with a fall in plasma amino acid concentrations. This was interpreted as indicating that leucine increased net protein synthesis. In our study, infusion of an equimolar amount of $\alpha$-ketoisocaproate or leucine (protocol I) was associated with a decrease in total plasma amino acid concentration of approximately the same amount. However, only $\alpha$-ketoisocaproate decreased urea nitrogen excretion. Thus, it is difficult to link a fall in plasma amino acid concentrations associated with leucine infusions to an increase in net protein synthesis.

In a previous study with a similar experimental design, we reported that the daily infusion of a combination of $\alpha$-ketoisocaproate, $\alpha$-ketoisovalerate, and $\alpha$-keto- $\beta$-methylvalerate (total $34 \mathrm{mmol} / \mathrm{d}$ ) decreased urea nitrogen and calculated total nitrogen excretion. On the basis of the present data, it is possible that this effect was attributable solely to the infused $\alpha$-ketoisocaproate because $11 \mathrm{mmol} / \mathrm{d}$ of this analogue had a similar effect on urinary nitrogen excretion (Table VI).

In the present study, measured changes in plasma concentration of acetoacetate, $\beta$-hydroxybutyrate, insulin, or acid-base parameters, did not appear to explain the changes in urinary nitrogen excretion induced by $\alpha$-ketoisocaproate. Sherwin et al. (19) reported that infusion of $\sim 40 \mathrm{~g} / \mathrm{d}$ of $\beta$-hydroxybutyrate into starving subjects decreased plasma alanine concentrations and urinary nitrogen excretion. It seems unlikely that the present results are related to this observation, because the potential quantity of ketones we infused as $\alpha$-ketoisocaproate was much smaller. Furthermore, after $\alpha$ ketoisocaproate infusions, blood ketones rose only 0.1 $\mathrm{mM}$ in the present study, whereas the observed rise during Sherwin's experiments (19) was 1.5-2.0 mM.

The results of our study show that $\alpha$-ketoisocaproate spares nitrogen during a fast. Investigation of the effect of this compound on nitrogen losses in disorders characterized by nitrogen wasting is warranted.

\section{ACKNOWLEDGMENTS}

We are indebted to Dr. O. E. Owen for the ketone body analyses and to Maureen G. Maguire for assistance with the statistical analysis. Sylvia Butler, Nancy Chambers, Valerie Hammond, and David Mearns provided technical assistance.

This work was supported by Program Project Grant AM 18020, Research Grant HE 3303, and Clinical Center Grant RR 35 from the National Institutes of Health.

\section{REFERENCES}

1. Fulks, R. M., J. B. Li, and A. L. Goldberg. 1975. Effects of insulin, glucose and amino acids on protein turnover in rat diaphragm. J. Biol. Chem. 250: 290-298.

2. Buse, M. G., and S. S. Reid. 1975. Leucine: a possible regulator of protein turnover in muscle. J. Clin. Invest. 58: $1251-1261$.

3. Freund, H., H. C. Hoover, S. Atamuriam, and J. E. Fischer. 1979. Infusion of the branched-chain amino acids in postoperative patients: anti-catabolic properties. Ann. Surg. 190: $18-23$.

4. Sherwin, R. S. 1978. Effect of starvation on the turnover and metabolic response to leucine. J. Clin. Invest. 61: 1471-1481.

5. Sapir, D. G., and M. Walser. 1977. Nitrogen-sparing induced early in starvation by infusion of branched-chain ketoacids. Metab. Clin. Exp. 26: 301-308.

6. Snedecor, G. W., and W. G. Cochran. 1967. Statistical Methods. 6th edition. Iowa State University Press, Ames, Iowa.

7. Felig, P., O. E. Owen, J. Wahren, and G. F. Cahill, Jr. 1969. Amino acid metabolism during prolonged starvation. J. Clin. Invest. 48: 584-594.

8. Walser, M., P. Lund, N. B. Ruderman, and A. W. Coulter. 1973. Synthesis of essential amino acids from their alpha-keto analogues by perfused rat liver and muscle. J. Clin. Invest. 52: 2865-2877.

9. Weber, F. L., Jr., W. C. Maddrey, and M. Walser. 1977. Amino acid metabolism by dog jejenum before and during infusion of keto-analogues. Am. J. Physiol. 232: E263E269.

10. Mitch, W. E., and W. Chan. 1978. Transamination of branched-chain ketoacids by isolated perfused rat kidney. Am. J. Physiol. 235: E47-E52.

11. Owen, O. E., and G. A. Reichard, Jr. 1971. Human forearm metabolism during starvation. J. Clin. Invest. 50: 1536- 1545.

12. Walajtys-Rode, E., K. E. Coll, and J. R. Williamson. 1979. Effects of branched-chain ketoacids on the metabolism of isolated rat liver cells. II. Interactions with gluconeogenesis and urea synthesis. J. Biol. Chem. 254: 11521-11529.

13. Garber, A. J., I. E. Karl, and D. M. Kipnis. 1976. Alanine and glutamine synthesis and release from skeletal muscle. J. Biol. Chem. 251: 826-835.

14. Pozefsky, T., and M. Walser. 1977. Effects of intra-arterial infusion of the keto-analogue of leucine on amino acid release by forearm muscle. Metab. Clin. Exp. 26: $807-815$.

15. Chang, T. W., and A. L. Goldberg. 1978. Leucine inhibits oxidation of glucose and pyruvate in skeletal muscle during fasting. J. Biol. Chem. 254: 3696-3701.

16. Garber, A. J., P. H. Menzel, G. Boden, and O. E. Owen. 1974. Hepatic ketogenesis and gluconeogenesis in humans. J. Clin. Invest. 54: 981-989.

17. Tischler, M. E., and A. L. Goldberg. 1980. Is leucine necessary for its regulatory effects on protein synthesis and degradation in skeletal and cardiac muscle? J. Biol. Chem. In press.

18. Owen, O. E., P. Felig, and G. F. Cahill, Jr. 1969. Liver and kidney metabolism during prolonged starvation. $J$. Clin. Invest. 48: 574-583.

19. Sherwin, R. S., R. G. Hendler, and P. Felig. 1975. Effect of ketone infusions on amino acid and nitrogen metabolism in man. J. Clin. Invest. 55: 1382-1390. 